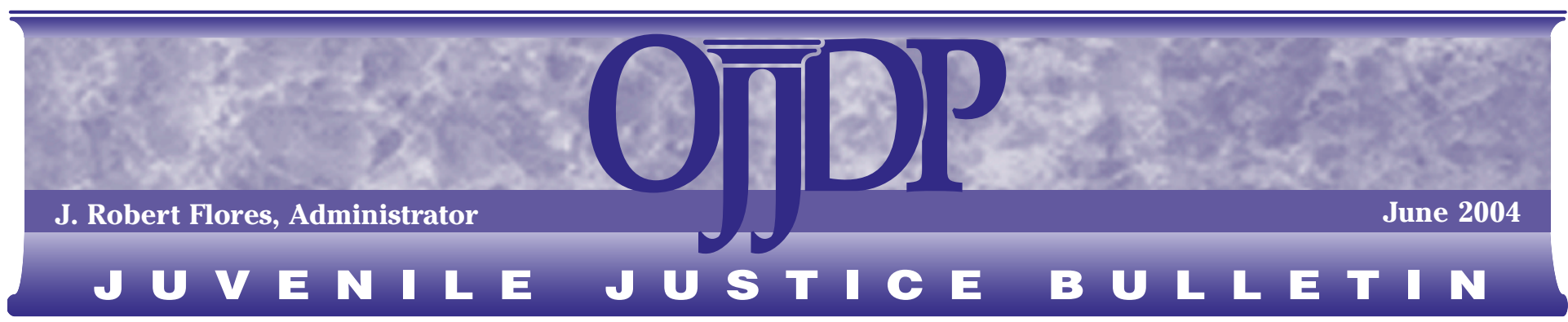

Office of Justice Programs • Partnerships for Safer Communities • www.ojp.usdoj.gov

\title{
Prostitution of Juveniles: Patterns From NIBRS
}

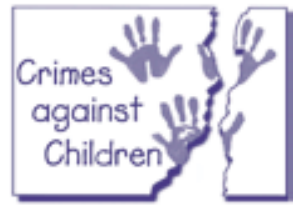

\section{David Finkelhor and Richard Ormrod}

The Office of Juvenile Justice and Delinquency Prevention (OJJDP) is committed to improving the justice system's response to crimes against children. OJJDP recognizes that children are at increased risk for crime victimization. Not only are children the victims of many of the same crimes that victimize adults, they are subject to other crimes, like child abuse and neglect, that are specific to childhood. The impact of these crimes on young victims can be devastating, and the violent or sexual victimization of children can often lead to an intergenerational cycle of violence and abuse. The purpose of OJJDP's Crimes Against Children Series is to improve and expand the nation's efforts to better serve child victims by presenting the latest information about child victimization, including analyses of crime victimization statistics, studies of child victims and their special needs, and descriptions of programs and approaches that address these needs.

Little statistical and research information exists about the prostitution of juveniles in its various forms. However, the emerging National Incident-Based Reporting System (NIBRS) provides a new opportunity for analyzing incidents of this problem that come to the attention of police. In the absence of other sources of information, the data about a limited number of cases from the 76 agencies in 13 states that are represented in NIBRS suggest some patterns of possible utility for those trying to identify and respond to the prostitution of juveniles. ${ }^{1}$

The following are highlights of the analysis presented in this Bulletin:
- Juvenile prostitution as encountered by police is more likely than adult prostitution to involve multiple offenders and more likely to occur indoors and in large urban areas.

- Police report more contacts with male juvenile prostitutes than with female juvenile prostitutes.

- Male juvenile prostitutes tend to be older than female juvenile prostitutes and more likely to operate outdoors.

- Police are less likely to arrest juvenile prostitutes than adult prostitutes, but more likely to arrest male juveniles than female juveniles, and more likely

\section{A Message From OJJDP}

The human degradation inherent in prostitution is always unacceptable but the victimization of children that takes place in juvenile prostitution is particularly disturbing. This Bulletin broadens our understanding of the problem by examining the prostitution of juveniles as it is known to law enforcement. Analyzing data from the FBI's National Incident-Based Reporting System, the authors provide a profile of juvenile prostitution, noting its distinctions from its adult counterpart.

Compared with adult prostitution, the prostitution of juveniles is more likely to occur in large cities and less likely to result in arrest. Juveniles involved in prostitution are more likely to work in groups than are adult prostitutes. There are also gender differences among juvenile prostitutes, with boys tending to be older than girls and more likely to operate outdoors. Understanding such differences can help us to develop more effective strategies to end the prostitution of juveniles.

The social and legal status of juveniles involved in prostitution is somewhat ambiguous. On the one hand, they are offenders involved in illegal and delinquent behavior. On the other, they are children who are being victimized by unscrupulous adults. Clearly, these youth are being harmed emotionally and are in considerable physical danger. Accordingly, from both a child protective and law enforcement strategy, our goal should be the same-the eradication of the sexual exploitation of youth. 
to refer female juveniles to other authorities, such as social services agencies.

- Police are more likely to categorize juveniles involved in prostitution as offenders than as crime victims, but those categorized as victims are more likely to be female and young.

$\checkmark$ Law enforcement agencies and policymakers need to engage in more analysis, planning, and coordination about how to respond to and record episodes of juvenile prostitution.

- Given the limitations of NIBRS data and the current lack of systematic information about the prostitution of juveniles, considerable additional research is needed.

\section{Background}

The prostitution of juveniles within the United States has proven a difficult problem to confront, whether by social welfare agencies, law enforcement organizations, or private social reform groups. This is due to the social and legal complexity of the problem and is compounded by a scarcity of reliable information on its nature and extent (Estes and Weiner, 2002; Fassett and Walsh, 1994; Flores, 1996; Klain, 1999; National Center for Missing and Exploited Children, 1992; The Hofstede Committee Report, 1999; Whitcomb, De Vos, and Smith, 1998).

The prostitution of juveniles occurs in a variety of contexts. Both international rings and interstate crime operations traffic young girls to distant places with promises of employment and money (Flowers, 2001). Parents advertise and prostitute their children over the Internet (The Hofstede Committee Report, 1999). Runaway and homeless youth on city streets are recruited by pimps or engage in "survival sex." Drug pushers force addicted teenagers to prostitute themselves as a condition for receiving drugs or a place to stay (Klain, 1999). As part of initiations, gangs may require members to engage in sex for money or other services (The Hofstede Committee Report, 1999). But also, acting on their own initiative or in the company of friends, young people may engage in casual or even frequent prostitution for money or for adventure (Rasmusson, 1999).

Juvenile prostitutes may be preadolescent children or older teenagers nearly indistinguishable from their adult counterparts.

\section{The National Incident-Based Reporting System}

The U.S. Department of Justice is replacing its long-established Uniform Crime Report (UCR) system with a more comprehensive National Incident-Based Reporting System (NIBRS). While UCR monitors only a limited number of index crimes and gathers few details on each crime event (except in the case of homicide), NIBRS collects a wide range of information on victims, offenders, and circumstances for a greater variety of offenses. Offenses tracked in NIBRS include violent crimes (e.g., homicide, assault, rape, robbery), property crimes (e.g., theft, arson, vandalism, fraud, and embezzlement), and crimes against society (e.g., drug offenses, gambling, prostitution). Moreover, NIBRS collects information on multiple victims, multiple offenders, and multiple crimes that may be part of the same episode.

Under the new system, as with the old, local law enforcement personnel compile information on crimes coming to their attention, and this information is aggregated in turn at the state and national levels. For a crime to be counted in the system, it simply needs to be reported and investigated. The incident does not need to be cleared or an arrest made, although unfounded reports are deleted from the record.

NIBRS holds great promise, but it is still far from a national system. Its implementation by the FBI began in 1988, and participation by states and local agencies is voluntary and incremental. By 1995, jurisdictions in 9 states had agencies contributing data; by 1997, the number was 12 ; and by the end of 2000 , jurisdictions in 19 states submitted reports, providing coverage for 14 percent of the nation's population and 11 percent of its crime. Only three states (Idaho, lowa, South Carolina) have participation from all local jurisdictions, and only three cities with a population greater than 500,000 (Austin, TX, and Memphis and Nashville, TN) are reporting. The crime experiences of large urban areas are thus particularly underrepresented. The system, therefore, is not yet nationally representative nor do its data represent national trends or national statistics. Nevertheless, the system is assembling large amounts of crime information and providing a richness of detail about juvenile offending and victimization that was previously unavailable. The patterns and associations these data reveal are real and represent the experiences of a large number of youth. For 2000 , the 19 participating states* reported more than $2,819,000$ crime incidents, with at least 267,164 involving an identified juvenile offender. Nevertheless, these patterns may change as more jurisdictions join the system.

More information about NIBRS data collection can be found at these Web sites:

(1) www.fbi.gov/ucr/ucr.htm, (2) www.search.org/nibrs/default.asp, and (3) www.jrsa.org/ibrrc/.

* Arkansas, Colorado, Connecticut, Idaho, lowa, Kansas, Kentucky, Massachusetts, Michigan, Nebraska, North Dakota, Ohio, South Carolina, Tennessee, Texas, Utah, Vermont, Virginia, West Virginia.

They may work individually or in groups, independently or under the control of pimps, parents, or other operators. The literature has tended to focus on girls, but male juvenile prostitutes have drawn increasing attention (Flowers, 2001). Knowledge about the backgrounds of juvenile prostitutes and the association of juvenile prostitution with child maltreatment, sexual abuse, and running away is better established than information on how these youth are dealt with by the justice and child welfare systems.

Part of the complexity of this problem relates to the social and legal status of the juveniles involved. Juvenile prostitutes can be viewed primarily as victims in the control of unscrupulous adults and commercial vice, but they can also be viewed as willing participants in an illegal trade and objectionable activity. Welfare and reform organizations tend to approach these juveniles as victims of specific exploiters and/or more general social conditions. The police, on the other hand, are more likely to view them as criminal offenders (Fassett and Walsh, 1994). In fact, the legal system can treat them as both offenders and victims. 


\section{Using NIBRS Data To Examine the Prostitution of Juveniles}

The information presented in this Bulletin on juvenile involvement in prostitution is based on data collected by the National Incident-Based Reporting System (NIBRS) for 1997, 1998, 1999, and 2000 (see discussion of the National IncidentBased Reporting System on p. 2). NIBRS is presently the only available source of geographically diverse and uniformly collected crime data that provides detailed descriptions of prostitution incidents, including the identity of individual prostitution offenders in terms of age and other personal characteristics. The prostitution incidents recorded by NIBRS represent only those that come to the attention of police.

The basic unit of data organization in NIBRS is the crime incident. An incident is defined as "one or more offenses committed by the same offender, or group of offenders acting in concert, at the same time and place." Thus, a single incident can be characterized by multiple offenses, multiple offenders, and, for those types of offenses for which NIBRS collects victim information, multiple victims.

The present analysis examines prostitution incidents that contain at least one of two types of prostitution offenses identified by NIBRS. The offenses are defined as (1) prostitution ("to unlawfully engage in sexual relations for profit") and (2) assisting or promoting prostitution ("to solicit customers or transport persons for prostitution purposes; to own, manage, or operate a dwelling or other establishment for the purpose of providing a place where prostitution is performed; or to otherwise assist or promote prostitution"). Either or both can occur in a single NIBRS incident. While this Bulletin treats any incident that contains either of these offenses as a prostitution incident, at times during data analysis it will be useful to distinguish between those where only "prostitution" occurred and those where "assisting prostitution" was recorded.

NIBRS records personal data on identified prostitution offenders, but treats prostitution offenses as "crimes against society" (rather than crimes against persons or property crimes) and provides no option for identifying or collecting data on individual victims of prostitution. It is important to note that the offenders identified for prostitution offenses in NIBRS are only those persons engaged in prostitution, not its patrons. Offenses such as "patronizing a prostitute" or "patronizing a house of prostitution" are categorized in NIBRS as "Type B, All Other Offenses," and offender information is only recorded if an arrest was made. Unfortunately, prostitution patrons cannot be distinguished from other, nonprostitution offenders who are also recorded in this NIBRS category (which includes those charged with a wide range of crimes, such as unlawful assembly, bigamy, contempt of court, criminal libel, harassment, invasion of privacy, jury tampering, littering, obstructing justice, perjury, reckless endangerment, sedition, smuggling, tax law violations, and illegal wiretapping).

In spite of these and other limitations set by data collection protocols, NIBRS allows two types of juvenile involvement with prostitution offenses to be identified. First, it reveals the presence of juvenile offenders in prostitution incidents. Because a NIBRS incident can include a "group of offenders acting in concert," multiple offenders identified in an incident are considered to be associated with all offenses occurring in the incident. When there are multiple offenses and multiple offenders, this leaves some uncertainty as to the exact role each offender played in each recorded offense. However, in most prostitution incidents with juvenile offenders (84 percent), either only a prostitution offense alone occurred or only a single offender was identified, thus removing any ambiguity as to the link between the offender and the offense. Thus, it is clear that most juvenile offenders identified in prostitution incidents in NIBRS were themselves engaged in prostitution.

Second, although juveniles are not recorded in NIBRS as victims of prostitution per se, they are sometimes identified as victims of other offenses (crimes against persons) that occurred in the same incident as a prostitution offense. Thus, juvenile victimizations associated with prostitution activity can be recognized. However, because the juvenile victim is linked to another specific offense in the incident and because NIBRS does not allow the recording of "child exploitation" as a type

continued on page 4
Uncertainty within law enforcement agencies on how to respond to the prostitution of juveniles and how to treat juvenile prostitutes has in turn contributed to a scarcity of reliable, consistent information about the problem. The variable status of a juvenile prostitute (victim or offender?) may discourage officers, especially if they are inexperienced in working with child welfare and juvenile justice systems, from recording a prostitution offense at all, or may lead them to charge the juvenile instead with another offense altogether (Fassett and Walsh, 1994; Klain, 1999). In the absence of resources to keep them off the streets, some police believe charging juveniles with a crime may be the only way to place them in a secure location.

One of the tools that may prove helpful in guiding law enforcement initiatives about the problem of juvenile prostitution is the FBI's NIBRS. This growing system, designed to replace the present Uniform Crime Report (UCR) system, allows, for the first time, the tracking of prostitution incidents involving juveniles across a large number of law enforcement jurisdictions. Although NIBRS data are far from nationally representative, they provide broad-based, uniform reports of juvenile prostitution activities that overcome many of the data limitations that have plagued past analyses of this problem. ${ }^{2}$ Consequently, the cases recorded in NIBRS merit careful examination to see what they might reveal about the problem as it is presently known to police, and how they might be used to help clarify the nature of the problem.

\section{Prostitution Incidents Known to Police}

Prostitution offenses are relatively scarce in police reports. Although 14,230 prostitution incidents are recorded in NIBRS data from 1997 through 2000, they represent only 0.17 percent of all crime incidents known to police. That is, about 2 out of every 1,000 incidents known to police involved prostitution.

As noted, in NIBRS juveniles can be associated with prostitution crimes as both offenders and victims. How these two categories differ is not entirely clear because NIBRS does not provide coding guidelines to police on this matter. Ambiguity exists because when a juvenile has sex with an adult in exchange for money, the juvenile may have committed a prostitution offense and may also be victim of a statutory or 


\section{Using NIBRS Data To Examine the Prostitution of Juveniles}

\section{continued from page 3}

of criminal activity associated with prostitution offenses themselves (which it does for pornography and other selected crimes), the nature of the link between a juvenile victim and the prostitution offense remains ambiguous and must be inferred from other characteristics of the incident.

This Bulletin explores both patterns of juvenile prostitution involvement recorded in NIBRS: involvement as an offender and involvement as a victim. For purposes of analysis, prostitution incidents involving juvenile offenders and prostitution incidents involving juvenile victims are treated as distinct sets of events, even though a small number of incidents (5 percent of all prostitution incidents involving juveniles) qualify in both categories. When an incident could qualify as a juvenile offender incident and a juvenile victim incident, it was counted in both categories for purposes of comparison.

In exploring prostitution incidents involving juvenile offenders, NIBRS data are used to construct statistical descriptions of the incidents and the offenders involved in them. Characteristics that can be described include offender age, gender, and race; numbers of offenders involved; age and gender mixes of offenders; times of day of incidents; and type of locations and places where incidents occur. Comparison of these characteristics with those of other types of crime incidents recorded in NIBRS (such as juvenile offender incidents that did not include prostitution and prostitution incidents that involved only adult offenders) can highlight what is distinctive and noteworthy about the prostitution of juveniles.

In addition, this analysis describes the characteristics of those juveniles categorized as victims in prostitution incidents, as well as the dynamics of their victimization. Of particular interest are the personal characteristics of juvenile victims found in prostitution incidents (e.g., age, gender, race) and how their patterns compare to those of juvenile prostitution offenders. Also of interest are the specific offenses committed against these victims, the nature of the offenders who committed them, the relationship that existed between a victim and an offender, and the conditions (such as time and place) in which the incident occurred. Once again, comparisons with other types of incidents and victims recorded in NIBRS can highlight distinctive and noteworthy characteristics of these incidents and the juvenile victims involved. Such comparisons can also provide ideas about how the juvenile victims found in these incidents are linked to the prostitution offense itself.

Although the number of incidents reported thus far within NIBRS is not large, NIBRS data is useful nonetheless to analyze for several reasons. First, NIBRS provides information about a topic on which very little systematic statistical and research data have been previously available. Second, it aggregates the experiences of a fairly large number of communities and police jurisdictions, avoiding biases that may be introduced by studies or analyses in single communities. Third, it provides an anticipatory look at data from a source that will be increasingly important as it becomes national in scope in the coming years.

Still, patterns from the analysis of NIBRS data in this Bulletin should be regarded with caution. They are based on a small number of cases from an unrepresentative sample of jurisdictions. In particular, the sample contains few large urban areas and border cities where such activity may flourish. Moreover, little is known about how police practices may bias what the statistics reveal (Fassett and Walsh, 1994). In addition, much juvenile prostitution is undoubtedly overlooked or fails to come to the attention of law enforcement. All this points to the need for more and better data and research on the prostitution of juveniles. other sex crime. Presumably, when juveniles are pimped by adults they will tend to be seen as victims, and when they take a more active role in soliciting sexual activities, they will tend to be seen as offenders. But some of the categorization may reflect arbitrary features such as the demeanor of the juveniles, the sympathy that individual police officers may have for them, or the policies of the jurisdiction in which the incident occurred. To help understand how law enforcement responds to the prostitution of juveniles, this Bulletin examines the juveniles categorized as both offenders and victims in prostitution incidents.

Of the 13,814 prostitution incidents in NIBRS that involved identified offenders of any age, 200 (1.4 percent) involved juvenile offenders. ${ }^{3}$ The numbers showed little change over the 4-year NIBRS data period examined in this study (1997-2000). Although this could suggest that prostitution activity and/or the police practices that bring those activities to light remained stable during those years, ${ }^{4}$ the limitations of NIBRS data make it unwise to draw any conclusions about trends without having a variety of additional sources of information.

In addition to the juvenile offender cases, juvenile victims were listed in 52 prostitution incidents during the 4-year study period. As with incidents involving juvenile offenders, the year-to-year numbers of incidents involving juvenile victims remained relatively stable.

Altogether, NIBRS data for 1997-2000 identify 241 prostitution incidents with either juvenile offenders, juvenile victims, or both (5 percent of incidents). Within these incidents are found 229 individual juvenile offenders and 61 individual juvenile victims. These cases span 13 states and 76 law enforcement jurisdictions. Although this is not a large number of incidents for typical crime statistical analysis, so few multijurisdictional analyses exist of police encounters with the prostitution of juveniles that this limited sample is worthy of analysis. In addition, the NIBRS system allows a contrast between the prostitution of juveniles and adult prostitution. 
Table 1: Comparison of Prostitution Incidents Involving Juvenile Offenders and Adult Offenders

Prostitution Incidents (\%)

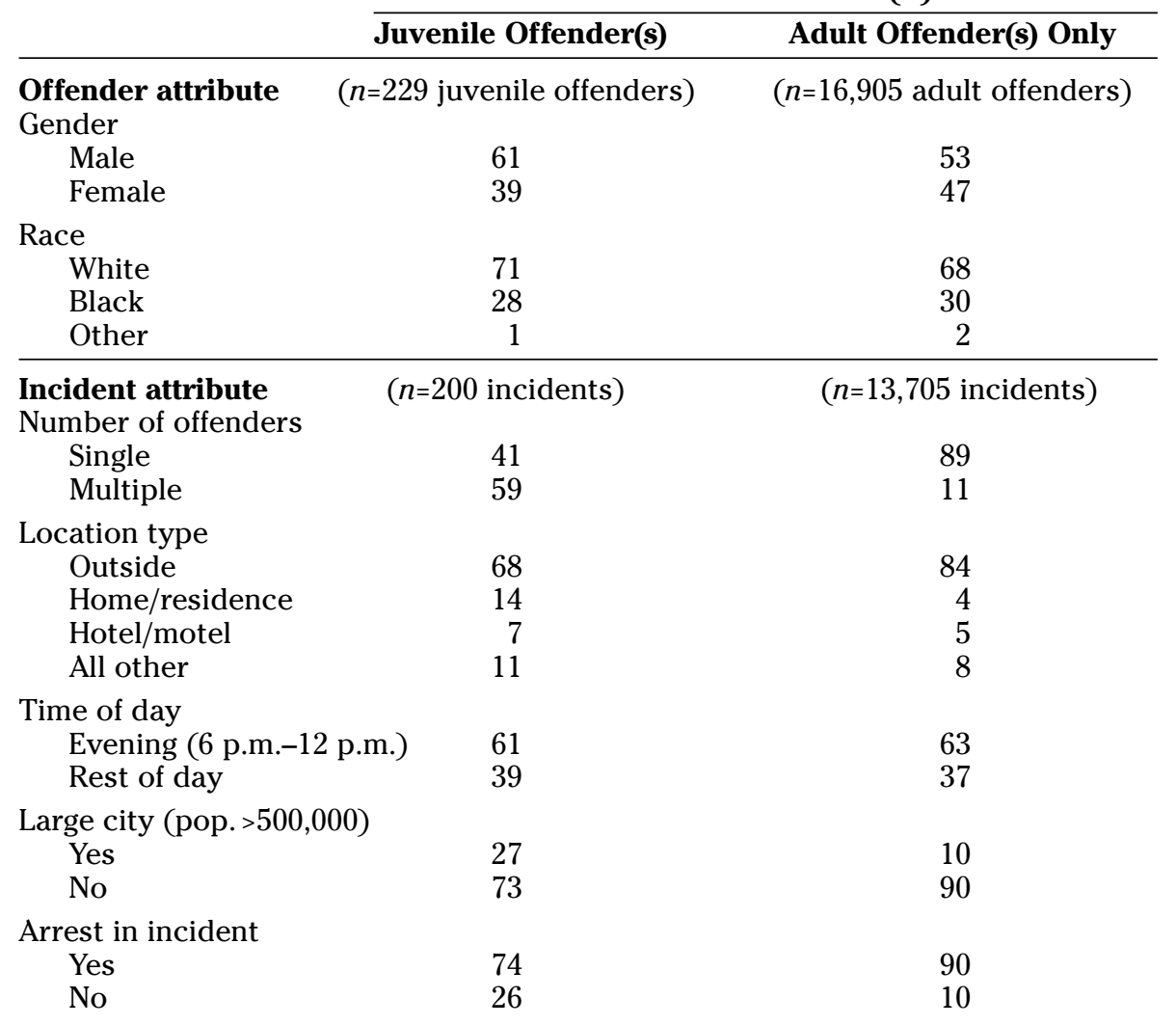

Source: Federal Bureau of Investigation, 1997-2000.

Figure 1: Seasonal Pattern of Crime Incidents

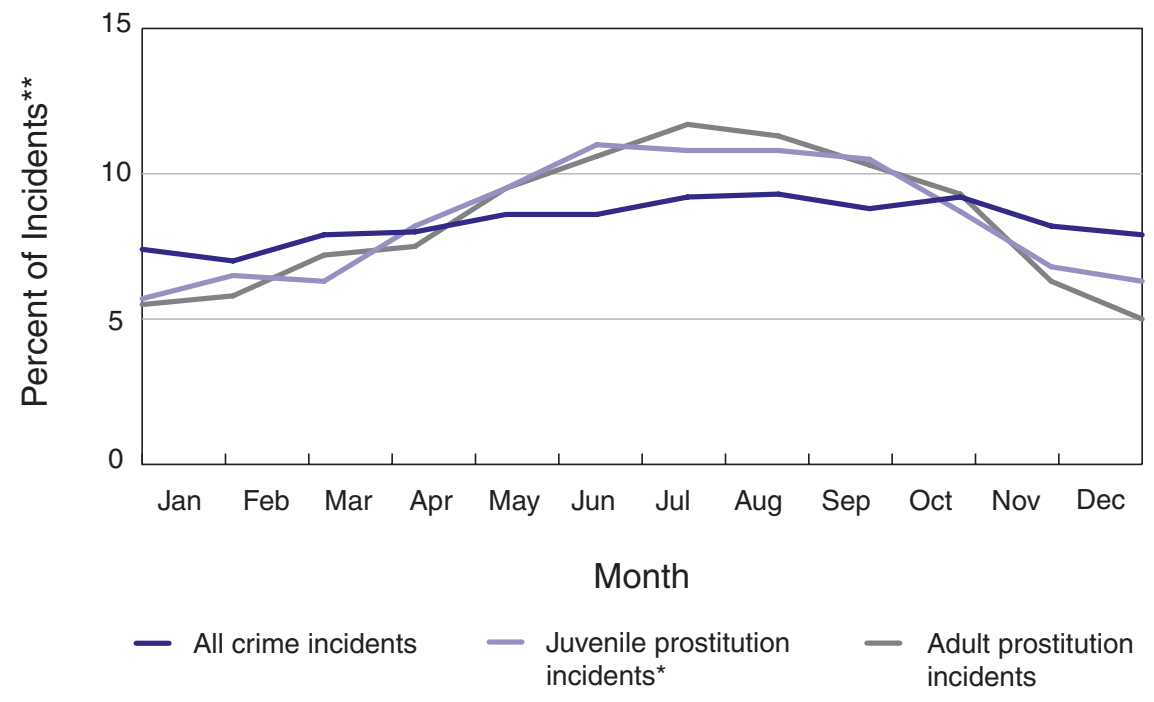

* Shown as 3-month running average for smoothing.

** Percentages calculated separately for each group.

Source: Federal Bureau of Investigation, 1997-2000.

\section{Prostitution Incidents With Juvenile Offenders}

Prostitution incidents with juvenile offenders were distinctive in a number of ways from prostitution in general. (The contrasts are presented first, and discussion of their implications occurs later in the Bulletin.) For one thing, juvenile prostitution offenders known to police were more often male (61 percent) than female (39 percent), a greater disproportion than among adult prostitution offenders (53 percent male and 47 percent female) (table 1). Second, juvenile prostitution offenders were most commonly encountered in multiple offender groups (59 percent of incidents). This contrasts with the adult offender pattern, which is composed overwhelmingly of single offender incidents (89 percent).

Although a majority (68 percent) of prostitution incidents involving juvenile offenders took place at an outside location (such as a highway, road, alley, field, woods, or parking lot), this was less frequent than for adult offenders, and juvenile incidents were considerably more likely to occur at homes and residences.

In terms of geographic context, the prostitution of juveniles was more a large city phenomenon than adult prostitution. Twenty-seven percent of all prostitution incidents involving juvenile offenders occurred in large cities compared to 10 percent of adult prostitution incidents. ${ }^{5}$

Finally, arrests were less likely to be made in prostitution incidents involving juvenile offenders than in incidents involving adult offenders (74 percent and 90 percent of incidents, respectively).

In other ways, the prostitution of juveniles did not differ considerably from adult prostitution (table 1). Both juvenile and adult offenders were predominantly white (71 percent and 68 percent, respectively). They both tended to be encountered by police in the evening (6 p.m. to midnight). And both followed a stronger seasonal pattern than crime in general, with prostitution occurring more frequently during the warmer months (May through September, see figure 1). The seasonal pattern in police-reported prostitution activity was even more pronounced for those jurisdictions located in states with colder winters. 


\section{Variation in the Prostitution of Juveniles}

Prostitution incidents involving different types of juvenile offenders may vary a great deal in their character. For example, girls have been portrayed as most often working for pimps (either male or female adults), whereas boys are described as usually working alone or in small groups without pimps (Flores, 1996; Klain, 1999; Whitcomb, De Vos, and Smith, 1998). The prostitution incidents recorded in NIBRS are consistent with such patterns, but cannot confirm them directly. One indicator of the presence of a pimp in an incident is the offense category "assisting or promoting prostitution," which includes soliciting customers or transporting persons for prostitution purposes. Unfortunately, this offense can also represent activities by other, nonpimping offenders-for example, the soliciting performed by a single prostitute working alone. Another indicator in NIBRS that can suggest the presence of a pimp working with a juvenile prostitute is the identification in the incident of both adult and juvenile offenders. It is plausible that an adult offender, particularly one a number of years older than the juvenile offender(s), signifies the presence of a pimp. However, the adult could be another prostitute and not a pimp.
To explore these patterns, the incidents were first divided into groups based on offender age (i.e., juvenile-only incidents and mixed-age incidents, see figure 2). These groups were further subdivided by the gender of the juvenile offender (male

\section{Figure 2: Offender Patterns in Prostitution Incidents Involving Juvenile Offenders}

\begin{tabular}{|c|c|c|}
\hline & Juvenile-Only Incidents & Mixed-Age Incidents \\
\hline $\begin{array}{l}\text { Male juvenile } \\
\text { offenders only }\end{array}$ & \begin{tabular}{lr}
\multicolumn{2}{c}{$\mathbf{5 0}$ Incidents } \\
Lone male offender & 43 \\
Multiple male offenders & 7
\end{tabular} & \begin{tabular}{l}
\multicolumn{1}{c}{$\mathbf{6 7}$ Incidents } \\
$\begin{array}{lr}\text { With adult male offender(s) } & 55 \\
\text { With adult female offender(s) } & 3 \\
\text { With adult male and female } \\
\text { offenders }\end{array}$ \\
\end{tabular} \\
\hline $\begin{array}{l}\text { Female juvenile } \\
\text { offenders only }\end{array}$ & \begin{tabular}{l}
\multicolumn{1}{c}{44 Incidents } \\
Lone female offender $\quad 39$ \\
Multiple female offenders $\quad 5$
\end{tabular} & \begin{tabular}{lr}
\multicolumn{1}{c}{36 Incidents } \\
With adult male offender(s) & 15 \\
With adult female offender(s) & 7 \\
With adult male and female \\
offenders
\end{tabular} \\
\hline $\begin{array}{l}\text { Both male and } \\
\text { female juvenile } \\
\text { offenders }\end{array}$ & $\begin{array}{l}\text { 2 Incidents } \\
\text { One male and } \\
\text { one female offender }\end{array}$ & $\begin{array}{l}1 \text { Incident } \\
\text { With adult male and } \\
\text { female offenders }\end{array}$ \\
\hline
\end{tabular}

\section{Table 2: Characteristics of Prostitution Incidents Involving Juvenile Offenders, by Type of Incident and Gender of Juvenile Offender}

Incidents (\%)

\begin{tabular}{|c|c|c|c|}
\hline \multicolumn{2}{|c|}{ Juvenile-Only } & \multicolumn{2}{|c|}{ Mixed-Age } \\
\hline Male Juvenile & Female Juvenile & Male Juvenile & Female Juvenile \\
\hline $\begin{array}{l}\text { Offenders Only } \\
(n=50 \text { incidents) }\end{array}$ & $\begin{array}{l}\text { Offenders Only } \\
(n=44 \text { incidents) }\end{array}$ & $\begin{array}{l}\text { Offenders Only } \\
(n=67 \text { incidents) }\end{array}$ & $\begin{array}{l}\text { Offenders Only } \\
(n=36 \text { incidents) }\end{array}$ \\
\hline
\end{tabular}

\section{Type of prostitution offense}

"Assisting or promoting" prostitution

"Prostitution" only

42

58

Age of juvenile offenders (\% of offenders)

$<12$ years

$12-13$ years

$14-15$ years

16-17 years

Location type

Outside

Hotel/motel

Home/residence

All other

Arrest in incident

Yes

No

Additional offense in incident

Yes

No
14

86

0

10

31

59

66

7

14

13

66

34

14

86
19

81

39

61

8

3

35

54

42

11

30

17

67

33

31

69

Source: Federal Bureau of Investigation, 1997-2000. 
Table 3: Prostitution Arrest Patterns

\begin{tabular}{lc} 
Arrestee/Offender & $\begin{array}{c}\text { Number of Identified } \\
\text { Offenders in } \\
\text { Group }\end{array}$ \\
\hline Prostitution Incidents
\end{tabular}

Number of
Prostitution
Arrestees

\begin{tabular}{c} 
Arrestees as \\
Percentage of \\
Offenders \\
\hline
\end{tabular}

\begin{tabular}{lrrr}
\hline All juveniles & 229 & 134 & 59 \\
Male juveniles & 140 & 88 & 63 \\
Female juveniles & 88 & 46 & 52 \\
All adults & 17,134 & 14,103 & 82 \\
Male adults & 8,891 & 7,522 & 85 \\
Female adults & 8,005 & 6,581 & 82
\end{tabular}

Source: Federal Bureau of Investigation, 1997-2000. prostitution (typically a drug-related or sex offense).

The two types of juvenile-only incidents (male juvenile offenders only and female juvenile offenders only) typically fell between the two types of mixed-age incidents in character, and were somewhat similar to each other. The most notable difference between them was the higher occurrence of "assisting prostitution" offenses in the incidents involving only male juveniles, described above. It may be that this difference reflects how the police encounter these juvenile offenders in the course of their investigations or patrols. If a pimp arranges a meeting between a female juvenile prostitute and a patron, the police may only encounter the prostitute and patron but not the pimp. The offense charged would be "prostitution" rather than "assisting prostitution." If, on the other hand, the police encounter the pimp in the process of soliciting, but without a prostitute present, the offense charged would be "assisting prostitution." It may be that a number of these pimps are male juveniles, or it may be that male juveniles more often solicit for themselves than do female juveniles.

An additional contrast associated with offender age and gender differences was the pattern of prostitution arrests reported in NIBRS. NIBRS not only records the age and gender of individual offenders identified in prostitution incidents, but also collects the same information for individual arrestees in those incidents. Since the arrest offense is catalogued for each arrestee, this allows those arrested for prostitution to be specifically identified. Thus, the relative numbers of offenders and arrestees in prostitution incidents can be compared in terms of age and gender.

Many fewer of the juvenile offenders were arrested than adult offenders (59 percent and 82 percent, respectively) (table 3 ). Among the juvenile offenders, males were arrested somewhat more often than females (63 percent and 52 percent, respectively). The differential treatment of male and female prostitutes by law enforcement extended beyond arrest disparities in that most female juveniles (74 percent) arrested for prostitution were subsequently referred to other authorities, whereas a majority ( 57 percent) of male juveniles arrested for prostitution were handled within the department (i.e., released to parents, released with warning, etc.). In interpreting gender differences, it should be kept in mind that dents, male juvenile offenders were primarily associated with male adult
Further differences distinguished the four types of incidents categorized in table 2 . ing male juveniles more often involved the oldest juvenile offenders (ages 16 and 17), were the most likely to occur at an outside location, and were the most likely to be linked to an arrest. In contrast, mixedage incidents involving female juveniles involved more younger juvenile offenders (ages 15 and younger), were the least likely to occur outside (more often tied to a home/residence or a hotel/motel location), and had the highest likelihood of containing an additional offense beyond 
female offenders were typically somewhat younger than male offenders, thus differences in the treatment of male and female juvenile offenders may be influenced by age and not just gender.

\section{Juvenile Victims in Prostitution Incidents}

As noted earlier, not all juveniles in prostitution incidents were identified as offenders. Juvenile victims also were reported in some prostitution episodes, but, as described earlier, the victims in these episodes are not categorized as victims of prostitution per se, but rather as victims of other offenses, such as sex crimes (see figure 3). This means that a juvenile victim's actual role in a prostitution incident is not always clear, nor is the victim's link to the prostitution offense. For example, an adult prostitution offender may commit a sex crime against a child, but not necessarily as part of the prostitution activity. It is clear, however, that prostitution incidents involving juvenile victims had their own distinctive patterns and were different in many ways from prostitution incidents involving juvenile offenders.

First, the juvenile victims in prostitution incidents were predominantly female

Figure 3: Offenses Committed Against Juvenile Victims in Prostitution Incidents

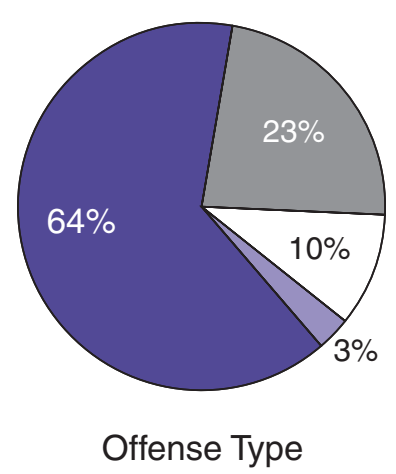

Violent crime: sexual

Violent crime: nonsexual

Nonviolent crime: sexual

Nonviolent crime: nonsexual

Source: Federal Bureau of Investigation, 1997-2000.
(72 percent) compared with the juvenile offenders who were disproportionately male (61 percent) (table 4). The victims were also younger, most (77 percent) 15 years old or younger, compared with the juvenile offenders, 69 percent of whom were 16 or 17 years old. One factor contributing to these age differences may be age-of-consent laws, which, in some states, do not allow juveniles to be considered the victims of statutory sex crimes after the age of 15 (Klain, 1999).

Prostitution incidents involving juvenile victims were also different according to the locales where they occurred. The predominant location (48 percent) was a home or residence and only 17 percent occurred outside. By contrast, incidents involving juvenile offenders occurred predominantly outside (68 percent) and much less frequently in homes and residences (14 percent). Prostitution incidents involving juvenile victims tended to occur much less frequently during the evening than those involving juvenile offenders (29 percent and 61 percent, respectively). And prostitution incidents involving juvenile victims were not nearly as often associated with large city environments as incidents involving juvenile offenders.

Prostitution incidents involving juvenile victims were also more likely than those involving juvenile offenders to involve adult offenders. Fully 90 percent of juvenile victim incidents involved an adult offender (table 5), compared with only 52 percent of juvenile offender incidents (104 of 200 incidents, see figure 2). In both types of incidents, the adult offenders were almost exclusively male. Specifically,

\section{Table 4: Comparison of Prostitution Incidents Involving Juvenile Offenders and Juvenile Victims}

\begin{tabular}{|c|c|c|}
\hline & \multicolumn{2}{|c|}{ Prostitution Incidents (\%) } \\
\hline & $\begin{array}{c}\text { Involving } \\
\text { Juvenile Offender(s) }\end{array}$ & $\begin{array}{c}\text { Involving } \\
\text { Juvenile Victim(s) }\end{array}$ \\
\hline Victim or offender attribute & ( $n=229$ offenders) & ( $n=61$ victims) \\
\hline \multicolumn{3}{|l|}{ Gender } \\
\hline Male & 61 & 28 \\
\hline Female & 39 & 72 \\
\hline \multicolumn{3}{|l|}{ Age } \\
\hline$<12$ years & 2 & 15 \\
\hline $12-13$ years & 6 & 18 \\
\hline $14-15$ years & 24 & 44 \\
\hline $16-17$ years & 69 & 23 \\
\hline \multicolumn{3}{|l|}{ Race } \\
\hline White & 71 & 74 \\
\hline Black & 28 & 24 \\
\hline Other & 1 & 2 \\
\hline Incident attribute & ( $n=200$ incidents) & ( $n=52$ incidents) \\
\hline \multicolumn{3}{|l|}{ Location type } \\
\hline Outside & 68 & 17 \\
\hline Home/residence & 14 & 48 \\
\hline Hotel/motel & 7 & 6 \\
\hline All other & 11 & 29 \\
\hline \multicolumn{3}{|l|}{ Time of day } \\
\hline Evening (6 p.m.-12 a.m.) & 61 & 29 \\
\hline Rest of day & 39 & 71 \\
\hline \multicolumn{3}{|l|}{ Large city (pop. $>500,000)$} \\
\hline Yes & 27 & 15 \\
\hline No & 73 & 85 \\
\hline \multicolumn{3}{|l|}{ Arrest in incident } \\
\hline Yes & 74 & 35 \\
\hline No & 26 & 65 \\
\hline
\end{tabular}

Source: Federal Bureau of Investigation, 1997-2000. 
94 percent of mixed-age incidents involving a juvenile victim also involved a male adult offender (table 5), while 90 percent of mixed-age incidents involving juvenile offenders also involved at least one male adult offender (94 of 104 incidents, see figure 2).

In spite of the frequent presence of adult male offenders in prostitution incidents involving juvenile victims, arrest rates were relatively low. Arrests were made in 35 percent of prostitution incidents involving juvenile victims (table 4), compared with 74 percent of prostitution incidents with juvenile offenders and 90 percent of those with only adult offenders (table 1). The higher percentage of arrests in juvenile offender cases probably reflects, at least in part, that police encounter these offenses more often outdoors with the activities in progress and offenders present. The juvenile victim cases, which occur less frequently in an outdoor location, involve more episodes that come to police attention through victim or third-party reports, so that the offender is not present, making an arrest difficult if not impossible.

Most juvenile victims knew their offenders (64 percent were victimized by acquaintances and 11 percent by family members) (table 5). And most of the victimizations suffered by juveniles at the hands of these offenders were violent crimes (87 percent), with a majority being forcible sex assaults (64 percent of all victimizations) (figure 3 ). Nonforcible sex offenses were also committed, so altogether forcible and nonforcible sex crimes were present in nearly three-quarters (74 percent) of the juvenile victimizations. ${ }^{6}$ Still, nearly a quarter of the victimizations (23 percent) consisted of nonsexual violence. (If the child was being prostituted in these cases, the actual sex crime against a child may not have yet occurred.) Little victim injury was reported in these victimizations (12 percent of cases) (table 5). The typical victim in these incidents was a lone 14year-old female who was the victim of a sex offense by an adult male acquaintance or family member that occurred during the daytime in a residence or hotel/motel.

\section{Implications}

NIBRS data, although limited, suggest that the prostitution of juveniles is a varied and complex problem that affects both male and female juveniles and both older and younger teenagers. Some of the juveniles appear to be engaged in prostitution on their own, some in groups with other

\section{Table 5: Characteristics of Prostitution Incidents Involving Juvenile Victims}

Incidents Involving Juvenile Victims (\%)

\begin{tabular}{lc}
\hline Incident attribute & $(n=52$ incidents) \\
Offender age group & 79 \\
Only adult & 11 \\
Adult and juvenile & 10 \\
Only juvenile & \\
Offender gender & 94 \\
$\quad$ Any male & 6 \\
Only female & \\
Number of victims & 83 \\
Single juvenile & 13 \\
Multiple juvenile & 4 \\
Multiple juvenile and adult & Victims (\%) \\
& $(n=61$ victims) \\
\hline Victimization attribute & 11 \\
Offender relationship to victim & 64 \\
Any family member & 25 \\
Acquaintance, no family & \\
Only stranger or unidentified & 12 \\
Any victim injury & 88 \\
Yes &
\end{tabular}

Source: Federal Bureau of Investigation, 1997-2000.

juveniles, and some in conjunction with adults. In a majority of cases, law enforcement appears to treat the juveniles involved in these incidents as offenders, but in some they appear to regard the juveniles entirely as victims.

In NIBRS data, the prostitution of juveniles differs from adult prostitution in that it is less likely to be engaged in alone, and somewhat more likely to be engaged in indoors and in large urban areas. It is less likely to result in an arrest. Like adult prostitution, juvenile prostitution offenses are more likely to occur in the summer months and during the evening hours. Some of the differences from adult prostitution, like its indoor occurrence, may suggest the need for new law enforcement strategies for tracking and uncovering juvenile prostitution.

Strong gender segregation appears to occur in the prostitution of juveniles. According to NIBRS data, the prostitution of male juveniles appears different from that of female juveniles. Males tend to be somewhat older, more likely to operate outdoors, somewhat more likely to be arrested, and less likely to be treated by the police as "victims." According to the literature, female juveniles are more likely to operate in conjunction with pimps, and the NIBRS data on adult offenders in incidents involving juveniles are consistent with this observation. However, a considerable number of prostitution incidents involving female juvenile offenders appear to have no identified adult or male offender. These incidents are more similar to incidents involving boys without adult offenders than they are to incidents involving girls with adult offenders.

It is primarily boys who have been described as working on their own or with same age peers (Flores, 1996; Klain, 1999), so the large number of incidents in the NIBRS data involving only female juveniles raises some questions. Girls may be working on their own without adult pimps more than they have in the past, or the pimps may be hard for the police to locate. The finding may also reflect something about police practices (i.e., how police typically find juvenile prostitutesby street patrols, complaint investigation, targeted investigations, etc.). The data do suggest, however, that the phenomenon of female juvenile prostitutes working alone may have been overlooked in discussions of the juvenile prostitution problem. Law enforcement may need to make sure that outmoded stereotypes do not compromise effective work on this issue. 
Another surprising finding from NIBRS data is the large percentage of juvenile prostitution offenders who are male (61 percent), even larger than the percentage of males in the adult prostitution offender population (53 percent). This contrasts with the literature on the prostitution of juveniles and with intervention efforts, which have for the most part concentrated on females (Fassett and Walsh, 1994; National Center for Missing and Exploited Children, 1992; The Hofstede Committee Report, 1999). Trend information from the UCR shows a growing proportion of male prostitution during the 1990s (Snyder, 2001; Snyder, Sickmund, and Poe-Yamagata, 1996). This may reflect an increasing visibility of young male prostitutes, or an increasing law enforcement concern about this group. But the crime data may also possibly exaggerate this aspect of the problem for several reasons. The willingness of young men to operate outdoors may make them more conspicuous to the police. Police may be more likely to crack down on male prostitutes, or they may be more likely to treat females as victims, as offenders of other kinds of crimes, or in ways that do not show up in crime statistics (Fassett and Walsh, 1994). The absence of data in NIBRS from most major urban areas may, in addition, distort the gender distribution (e.g., if females are more common in cities). Moreover, some of the male juveniles who are listed as prostitution offenders may be playing other roles than actually prostituting themselves, such as pimping or procuring. Nonetheless, the NIBRS data do suggest that the role of male juveniles in prostitution, whether as pimps, procurers, or prostitutes, needs more attention from practitioners and researchers. However, before dramatic policy changes are made, more inquiry is needed from more jurisdictions to confirm these results.

The other important issue raised by the NIBRS data concerns the nature of law enforcement treatment of juvenile prostitutes. When discussed as a social problem, juvenile prostitutes are generally regarded as victims. But in police data on prostitution incidents, juveniles appear considerably more often as offenders than victims. Older teens and males, in particular, are considerably less likely to be categorized as victims. The NIBRS data may simply reflect the fact that police are not provided with categories adequate to code the true nature of the episodes. But it may also be that in the eyes of law enforcement, juvenile prostitutes are more often seen as offenders than victims. For effective intervention in this problem, it may be important for all of the agencies involved to arrive at a common analysis. This suggests the need for both additional research to clarify the nature of the problem, and forthright discussions in a common forum.

As this Bulletin demonstrates, NIBRS data offer new insights into the problem of juvenile prostitution. Furthermore, the value of these data can be amplified if police officers fully report every contact they have with a prostitution offense. For this to occur, both NIBRS training practice and individual agency protocols may need to emphasize the prostitution of juveniles as an important social problem in need of a solution. Data quality, and detail, can also be improved by changing some NIBRS coding practices. For example, "pimping" could be identified as a distinct prostitution offense, separate from "assisting or promoting," and a Type Criminal Activity code (which presently exists in the system and includes "exploiting children") could be permitted for prostitution offenses. Of course, NIBRS data will automatically become more representative of national patterns as participation by law enforcement agencies continues to expand, and this prospect will make them more valuable. As NIBRS data become national, they may be very useful for tracking historical and geographic trends in juvenile prostitution and for evaluating the impact of public policy.

However, the potential utility of NIBRS data does not reduce the need for considerable additional research on the problem of juvenile prostitution-both short-term and long-term studies. Such research should focus on the epidemiology of the problem, the variety of forms that it takes, the social and geographic contexts in which it occurs, and the life histories of juveniles both before and after their involvement in prostitution. In addition, considerable research attention needs to be paid to law enforcement practices, other interventions directed at the problem, and the consequences of these actions. This information is necessary to develop an effective public policy that addresses the prostitution of juveniles.

\section{Notes}

1. This Bulletin defines prostitution incidents as those incidents that contain at least one of two types of prostitution offenses identified by NIBRS. The offenses are defined as (1) prostitution ("to unlawfully engage in sexual relations for profit") and (2) assisting or promoting prostitution ("to solicit customers or transport persons for prostitution purposes; to own, manage, or operate a dwelling or other establishment for the purpose of providing a place where prostitution is performed; or to otherwise assist or promote prostitution"). Either or both can occur in a single NIBRS incident. While this Bulletin treats any incident that contains either of these offenses as a prostitution incident, at times during data analysis it will be useful to distinguish between those where only "prostitution" occurred and those where "assisting prostitution" was recorded. It is important to note that the offenders identified for prostitution offenses in NIBRS are only those engaged in prostitution, not its patrons. (See "Using NIBRS Data To Examine the Prostitution of Juveniles" on page 3 for more information.)

2. Most discussions of the prostitution of juveniles rely heavily on anecdotal case studies, often gathered from individual police officers or derived from interviews with limited populations of juvenile prostitutes, such as shelter residents or correctional facility inmates. Statistics on the prostitution of juveniles have often been based on guesswork (Ennew et al., 1996; Estes and Weiner, 2002; Rasmusson, 1999).

3. In 416 incidents, offender age was not specified in NIBRS data.

4. Similar stability is evident in the numbers of juveniles arrested for prostitution as reported in UCR in recent years (Sickmund, Snyder, and Poe-Yamagata, 1997; Snyder, 2001; Snyder, Sickmund, and PoeYamagata, 1996).

5 . Only 3 percent of NIBRS's juvenile offenses came from large city locales. This suggests that if large cities were appropriately represented in NIBRS, which they are not, the percent of juvenile offender prostitution from those areas would be considerably larger.

6. In NIBRS, a forcible sex offense is defined as "any sexual act directed at another person, forcibly and/or against that person's will; or not forcibly or against the person's will where the victim is incapable of giving consent." The specific forcible sex offenses are rape, sodomy, sexual assault with an object, and fondling. A nonforcible sex offense is defined as "unlawful, nonforcible sexual intercourse." The specific nonforcible sex offenses are incest and statutory rape. 


\section{References}

Ennew, J., Gopal, K., Heeran, J., and Montgomery, H. 1996. Children and Prostitution. New York, NY: UNICEF.

Estes, R.J., and Weiner, N.A. 2002. The Commercial Sexual Exploitation of Children in the U.S., Canada, and Mexico. Philadelphia, PA: University of Pennsylvania, School of Social Work, Center for the Study of Youth Policy. Retrieved May 7, 2003, from the Web: http://caster.ssw. upenn.edu/ restes/CSEC.htm.

Fassett, B., and Walsh, B. 1994. Juvenile prostitution: An overlooked form of child sexual abuse. The APSAC Advisor 7(1):9.

Federal Bureau of Investigation. 19972000. National Incident-Based Reporting System [computer file]. Compiled by the U.S. Department of Justice, Federal Bureau of Investigation. Produced and distributed by the Inter-university Consortium for Political and Social Research (ICPSR). Ann Arbor, MI: ICPSR.

Flores, R. 1996. Child Prostitution in the United States-Forced Labor: The Prostitution of Children. Washington, DC: U.S. Department of Labor, Bureau of International Labor Affairs, The Women's Bureau, and the U.S. Department of State, Bureau of Democracy, Human Rights and Labor.

Flowers, R.B. 2001. Runaway Kids and Teenage Prostitution. Westport, CT: Greenwood Press.
The Hofstede Committee Report. 1999. Juvenile Prostitution in Minnesota. St. Paul, MN: Minnesota Attorney General's Office.

Klain, E.J. 1999. Prostitution of Children and Child-Sex Tourism: An Analysis of Domestic and International Responses. Alexandria, VA: National Center for Missing and Exploited Children.

National Center for Missing and Exploited Children. 1992. Female Juvenile Prostitution: Problem and Response. Alexandria, VA: National Center for Missing and Exploited Children.

Rasmusson, A. 1999. Commercial Sexual Exploitation of Children: A Literature Review. Minneapolis, MN: The Alliance for Speaking Truths on Prostitution and The Center for Urban and Regional Affairs.

Sickmund, M., Snyder, H.N., and PoeYamagata, E. 1997. Juvenile Offenders and Victims: 1997 Update on Violence. Statistics Summary. Washington, DC: U.S. Department of Justice, Office of Justice Programs, Office of Juvenile Justice and Delinquency Prevention.

Snyder, H. 2001. Law Enforcement and Juvenile Crime. Bulletin. Washington, DC: U.S. Department of Justice, Office of Justice Programs, Office of Juvenile Justice and Delinquency Prevention.

Snyder, H.N., Sickmund, M., and PoeYamagata, E. 1996. Juvenile Offenders and Victims: 1996 Update on Violence. Statistics Summary. Washington, DC: U.S.
Department of Justice, Office of Justice Programs, Office of Juvenile Justice and Delinquency Prevention.

Whitcomb, D., De Vos, E., and Smith, B. 1998. Program To Increase Understanding of Child Sexual Exploitation. Final Report. Washington, DC: U.S. Department of Justice, Office of Justice Programs, Office of Juvenile Justice and Delinquency Prevention.

This Bulletin was prepared under grant number 98-JN-FX-0012 from the Office of Juvenile Justice and Delinquency Prevention, U.S. Department of Justice.

Points of view or opinions expressed in this document are those of the authors and do not necessarily represent the official position or policies of OJJDP or the U.S. Department of Justice.

The Office of Juvenile Justice and Delinquency Prevention is a component of the Office of Justice Programs, which also includes the Bureau of Justice Assistance, the Bureau of Justice Statistics, the National Institute of Justice, and the Office for Victims of Crime.

\section{Acknowledgments}

This Bulletin was prepared by David Finkelhor, Ph.D., Professor of Sociology and Director, Crimes against Children Research Center, University of New Hampshire, and Richard Ormrod, Ph.D., Research Professor, Crimes against Children Research Center, University of New Hampshire.

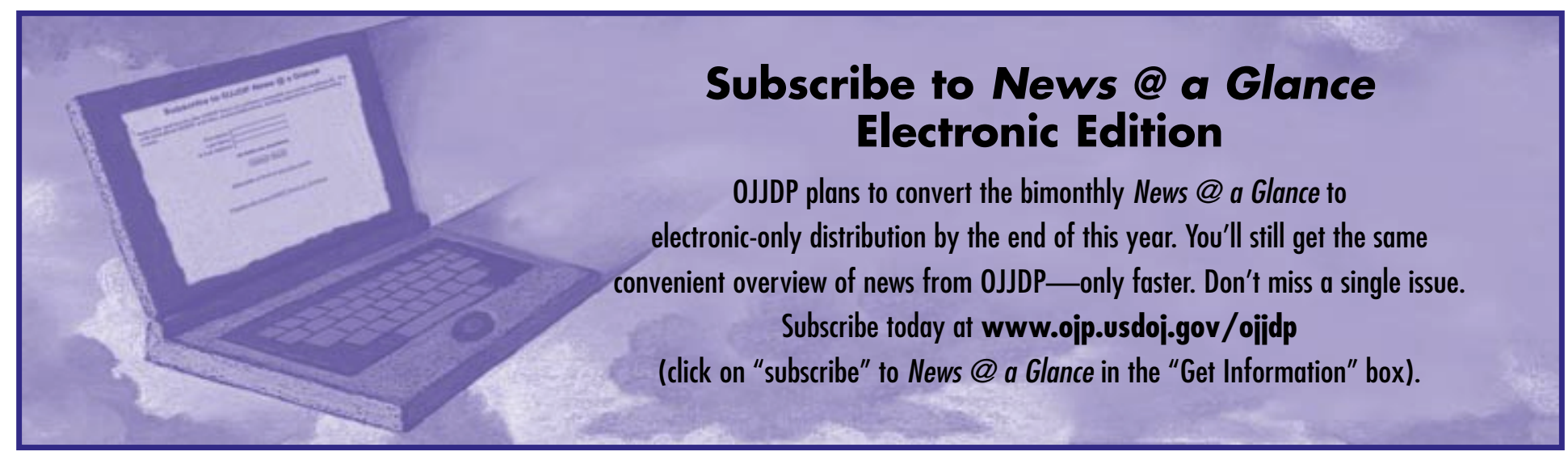


Washington, DC 20531

Official Business

Penalty for Private Use $\$ 300$ 